\title{
ANALYSIS OF FAST EXCITATORY POSTSYNAPTIC CURRENTS IN BULLFROG PARASYMPATHETIC GANGLION CELLS ${ }^{1}$
}

\author{
ELIZABETH A. CONNOR ${ }^{2}$ AND RODNEY L. PARSONS ${ }^{3}$ \\ Department of Anatomy and Neurobiology, University of Vermont College of Medicine, Burlington, Vermont 05405
}

Received November 17, 1982; Revised March 22, 1983; Accepted May 3, 1983

\begin{abstract}
Excitatory postsynaptic currents (EPSCs), miniature excitatory postsynaptic currents (MEPSCs), and acetylcholine-induced current fluctuations (noise) have been studied in voltage-clamped bullfrog parasympathetic ganglion cells of the atrial septum. EPSCs were also recorded from voltage-clamped sympathetic B cells and, in general, it was found that the basic properties of the EPSCs are similar in both parasympathetic and sympathetic B cells. For parasympathetic cells, the EPSC reached a peak amplitude of several nanoamperes within $3 \mathrm{msec}$ and decayed exponentially. For 31 cells voltage-clamped to $-50 \mathrm{mV}\left(22\right.$ to $23^{\circ} \mathrm{C}$ ), peak amplitude was $-4.3 \pm 1.4 \mathrm{nA}$ (mean $\pm \mathrm{SD}$ ) and the decay time constant, $\tau$, was $5.6 \pm 1.0 \mathrm{msec}$. $\tau$ was independent of EPSC amplitude at a set voltage but increased with hyperpolarization, the coefficient of voltage dependence being $-0.0070 \pm 0.0025$ $\mathrm{mV}^{-1}$ in 13 cells ( 21 to $23^{\circ} \mathrm{C}$ ). The EPSC amplitude-voltage relationship was linear between -30 and $-90 \mathrm{mV}$. The reversal potential, determined by interpolation, was $-4.0 \pm 6.7 \mathrm{mV}(n=11)$. The EPSC $\tau$ had a $Q_{10}$ equal to 2.9. Blocking the acetylcholinesterase with methane sulfonyl fluoride (MSF) pretreatment prolonged EPSC decay but decreased EPSC amplitude. In addition, EPSC decay after MSF treatment deviated from a single exponential function. MEPSCs exhibited decay characteristics very similar to those of EPSCs recorded at the same voltage and temperature. Acetylcholine-induced current fluctuations were well described by a single Lorentzian function with the estimated mean channel open time $\left(\tau_{\text {noise }}\right)$ very similar to the EPSC decay time constant. Estimates of the single channel conductance were lower than that reported previously for the motor endplate, the values in ganglion cells ranging betweem 5.4 and $14.9 \mathrm{pS}$. The similarity of the values of $\tau_{\text {FPSC }}, \tau_{\text {MFPSC}}$, and $\tau_{\text {noise }}$ supports the view that the decay time course of parasympathetic ganglionic EPSCs is primarily determined by the kinetics of receptor-channel gating.
\end{abstract}

Vertebrate autonomic ganglia have proved to be useful model preparations for numerous electrophysiological studies of voltage-dependent and chemically gated membrane conductances (Kuba and Koketsu, 1978; Adams, 1982). We have used the amphibian sympathetic ganglion cell to analyze the basic biophysical and pharmacological properties of cholinergically gated responses at a vertebrate neuronal synapse (MacDermott et al., 1980; Connor and Parsons, 1983; Connor et al., 1983). The results of our initial studies provide strong, albeit indirect evidence that the time course of the ganglionic excitatory

\footnotetext{
${ }^{1}$ We thank Dr. Jerome Fiekers for his helpful comments during the preparation of the manuscript. This work was supported by United States Public Health Service Grant NS-14552 and a Muscular Dystrophy Association grant.

${ }^{2}$ Present address: Department of Neurobiology, Stanford University School of Medicine, Stanford, CA 94305.

${ }^{3}$ To whom correspondence should be addressed.
}

postsynaptic current (EPSC) decay is primarily determined by the kinetics of the receptor-channel complex rather than hydrolysis or diffusion of transmitter away from the postsynaptic receptors (MacDermott et al., 1980). Unfortunately, in sympathetic ganglion cells we have not been able to test this conclusion directly by an analysis of miniature EPSC (MEPSC) decay characteristics or acetylcholine (ACh)-induced current fluctuations ("noise") as has been done in other preparations (Anderson and Stevens, 1973; Gage and McBurney, 1975; Dionne and Parsons, 1981).

Recently, we found that we could accurately measure MEPSCs and ACh-induced "noise" in voltage-clamped amphibian parasympathetic ganglion cells. Consequently, we have compared the properties of the evoked EPSC to those of the spontaneous MEPSC and ACh "noise" in parasympathetic ganglion cells to establish the rate-limiting step for ganglionic EPSC decay. In addition, as part of this study, we have compared the 
basic biophysical and pharmacological properties of EPSCs recorded from either parasympathetic or sympathetic ganglion cells taken from the same animal.

Our results indicate that the basic properties of amphibian parasympathetic cell EPSCs are very similar to those reported previously for bullfrog sympathetic ganglion cells (Kuba and Nishi, 1979; MacDermott et al., 1980). Furthermore, estimates of the mean channel open time obtained from an analysis of ACh-induced "noise" are very close to the EPSC or MEPSC decay time constant. This observation provides direct evidence in support of the view that in amphibian autonomic ganglion cells the EPSC decay time course is primarily controlled by the kinetics of receptor-channel gating.

\section{Materials and Methods}

All experiments were done in vitro using either parasympathetic ganglion cells of the atrial septum or B cells of the VIIIth, IXth, and Xth sympathetic ganglia from the bullfrog, Rana catesbeiana. The procedures for dissection of the sympathetic ganglia followed those reported previously (MacDermott et al., 1980), and procedures for the interatrial septum followed those detailed by McMahan and Kuffler (1971) and Dennis et al. (1971). The isolated preparations were pinned out in a Sylgardcoated Petri dish. To facilitate recording from parasympathetic cells, spontaneous beating of the isolated septum was eliminated by carefully excising or crushing the areas in which contractions appeared to originate. Both preparations were cleaned of excess connective tissue by carefully teasing away as many of the covering layers as possible.

All experiments were performed using preparations maintained in a HEPES ( $N$-(2-hydroxyethyl)-1-piperazine- $\mathrm{N}$-2-ethanesulfonic acid)-buffered solution (mM: $\mathrm{NaCL}, 120 ; \mathrm{KCl}, 2.5 ; \mathrm{CaCl}_{2}, 1.8 ; \mathrm{HEPES}, 1.0 ; \mathrm{pH} 7.3$ ). Bath temperature was controlled by circulating ethylene glycol at a desired temperature. Methane sulfonyl fluoride (MSF) was used in a few experiments and was added directly to the bathing solution at a final concentration of $10 \mathrm{~mm}$ for $1 \mathrm{hr}$. The MSF-containing solution was then replaced with the control solution and EPSCs were recorded.

The preparations were mounted on the stage of a compound microscope so that individual ganglion cells could be identified under brightfield illumination at $x$ 150 to 200 . The cell bodies were readily located and impaled with two glass microelectrodes filled with $3 \mathbf{M}$ $\mathrm{KCl}$ and having resistances of 10 to 20 megohms. The cells were voltage-clamped using a two-microelectrode voltage clamp as described previously (MacDermott et al., 1980; Dionne and Parsons, 1981). To collect EPSCs, the respective preganglionic nerves were stimulated at a constant frequency of $0.38 \mathrm{~Hz}$. Parasympathetic cells generally could be voltage-clamped between -90 and -30 $\mathrm{mV}$. In approximately one-third of the parasympathetic cells studied, it was possible to voltage clamp individual cells to positive levels of membrane potential. Sympathetic ganglion cells generally could be voltage-clamped to more negative values of membrane potential. In both preparations, EPSC characteristics remained constant during an individual experiment. Furthermore, cell deterioration was accompanied by a very rapid, large increase in holding current during which the impalement was lost and the cell was discarded. As a consequence, data were used only from cells in which EPSCs obtained after hyperpolarization exhibited characteristics similar to those obtained initially at the same voltage.

Individual EPSCs were filtered at $2 \mathrm{kHz}$, digitized, and stored by a PDP 11/03 computer (Digital Corp., Marlboro, MA). All of the results reported here were derived from averaged EPSCs (4 to 10 responses). However, under all conditions, each individual EPSC was similar to the averaged response. The criteria for determining acceptable responses under voltage clamp were identical to those used in our previous study of sympathetic ganglion cells (MacDermott et al., 1980).

For the analysis of $\mathrm{ACh}$-induced current fluctuations (noise), ACh was applied by iontophoresis onto the somal surface of parasympathetic cells. The iontophoretic application was controlled by a constant current feedback circuit (Dionne, 1976; Dionne and Parsons, 1981). Current fluctuations were recorded digitally and the mean power spectrum was computed using procedures described previously by Dionne and Parsons (1981). For determination of spectral shape, 25 to $50 \mathrm{ACh}$-induced current fluctuations were averaged and Fourier transformed to obtain spectral density as a function of frequency. Averaged spectra of the background fluctuations recorded just before agonist application were subtracted from the ACh-induced fluctuations.

The spectral density of the ACh-induced current fluctuations could be fit reasonably by a single Lorentzian function,

$$
S(f)=S(0) /\left(1+f / f_{c}\right)^{2}
$$

where $f_{c}$ is the cutoff frequency at which $S(f)$ has decreased to half its zero frequency asymptote. Two parameters of elementary events, mean channel open time $\left(\tau_{\text {noise }}\right)$ and mean single channel conductance $(\gamma)$ were estimated from the noise spectrum using the following relationships.

$$
\tau_{\text {noise }}=\frac{1}{2 \pi f_{c}}
$$

and

$$
\gamma=\frac{S(0)}{2 \vec{\mu}\left(V-V_{r}\right) \tau_{\text {noise }}}
$$

where $S(0)$ is the plateau value of the spectrum in the low frequency range, $\bar{\mu}$ is the mean ACh-induced current, and $V-V_{r}$ is the driving force (Anderson and Stevens, 1973).

All average values cited in the text and in tables are mean $\pm \mathrm{SD}$ with the number of cells in parentheses.

\section{Results}

Characteristics of the fast EPSC in parasympathetic cells. EPSCs, recorded in voltage-clamped amphibian parasympathetic cells following vagal stimulation, rose to a peak value within $3 \mathrm{msec}$ and, in the majority of cells, decayed exponentially. The peak amplitude of the 
parasympathetic EPSC was a few nanoamperes. For instance, in 31 cells voltage-clamped to $-50 \mathrm{mV}$, the peak size at 22 to $23^{\circ} \mathrm{C}$ was $-4.3 \pm 1.4 \mathrm{nA}$.

Averaged EPSCs obtained at three different voltages from the same cell are shown in Figure 1. The exponential nature of the EPSC decay in these examples is indicated by the linearity of the current values plotted
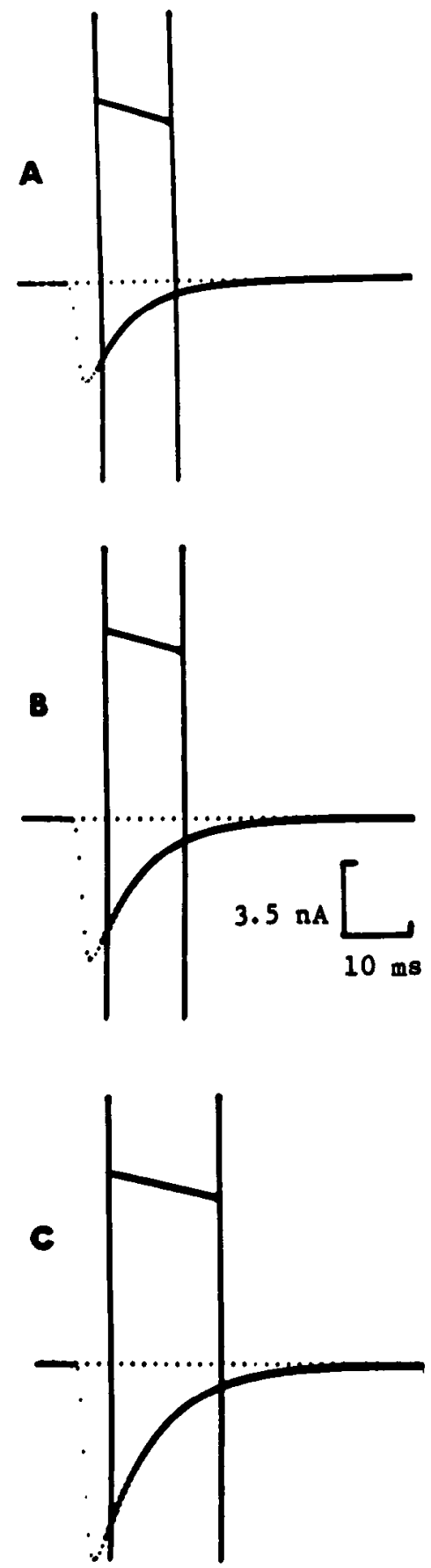

Figure 1. Averaged EPSCs recorded from a parasympathetic ganglion cell voltage-clamped to $-50 \mathrm{mV}(A),-70 \mathrm{mV}(B)$, and $-90 \mathrm{mV}(C)$. In each example, the decay phase of the currents is plotted semilogarithmically as a function of time above the current trace. The calculated exponential is displayed on the falling phase of each current trace. The temperature was $\sim 22^{\circ} \mathrm{C}$. Traces are the average of six events in $A$ and $B$ and five events in $C$. semilogarithmically above each record. The decay time constant $\tau$ was estimated from a linear least squares regression of the logarithm of current decay. The linear fit is superimposed on the data points above each trace. This analysis indicated that for most of the EPSC decay phase, the time course was described adequately by the single exponential expression:

$$
\operatorname{EPSC}(t)=\operatorname{EPSC}(0) \exp (-t / \tau)
$$

In example $A$ of Figure 1, recorded at $-50 \mathrm{mV}, \tau$ was 6.8 msec. The average value of $\tau$ in 31 cells voltage-clamped to $-50 \mathrm{mV}$ was $5.6 \pm 1.0 \mathrm{msec}$ at 22 to $23^{\circ} \mathrm{C}$.

In 5 of 65 cells voltage-clamped to $-50 \mathrm{mV}$ (18 to $23^{\circ} \mathrm{C}$ ), the decay phase deviated from a single exponential. The EPSCs of these cells were more accurately described by fitting the decay phase as the sum of two exponential components. EPSC decay in these cells remained complex throughout the period of impalement. There was no indication that these cells were inadequately voltage-clamped or excessively injured during impalement (i.e., no marked difference in holding current from other cells not exhibiting a complex decay). The results from these cells have not been included in the present analysis.

EPSC amplitude varied considerably between cells (range -1.1 to $-7.0 \mathrm{nA}$, at $-50 \mathrm{mV}$ ), but the rate of EPSC decay was independent of peak current amplitude. Figure 2 is a plot of $\tau$ versus peak EPSC amplitude for 31 cells voltage-clamped to $-50 \mathrm{mV}$ at 22 to $23^{\circ} \mathrm{C}$ which shows that the EPSC decay time constant is not a function of EPSC amplitude.

Spontaneous MEPSCs were observed in some cells. Often, when present, their frequency was higher than reported previously; thus it is probable that the preganglionic nerve terminal was stimulated mechanically during microelectrode impalement (Dennis et al., 1971). We have been unable to record both EPSCs and MEPSCs in the same cell because synaptic transmission often did not occur in those cells with an increased MEPSC frequency. In most cases the MEPSC amplitudes at membrane potentials between -50 and $-70 \mathrm{mV}$ were too small to determine accurately the distribution of peak amplitude and the decay time course. We estimated that for cells voltage-clamped to $-60 \mathrm{mV}$, the MEPSC am-

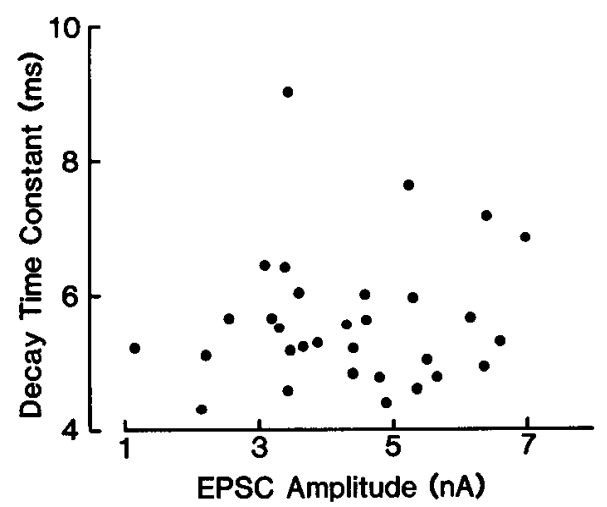

Figure 2. The EPSC decay time constant $(\tau)$ is plotted as a function of peak EPSC amplitude for 31 parasympathetic cells voltage-clamped to $-50 \mathrm{mV}$ at 22 to $23^{\circ} \mathrm{C}$. 
plitude ranged between 0.05 and $0.15 \mathrm{nA}$. An example record showing a series of MEPCs recorded from one cell voltage-clamped to $-60 \mathrm{mV}$ is presented in Figure $3 A$. In a few cells which were voltage-clamped to more hyperpolarized levels, the MEPSC amplitude was sufficient to allow analysis of the decay characteristics. An example from one of these cells is shown in figure $3 B$. This trace is an averaged MEPSC (18 individual MEPSCs) recorded at $-90 \mathrm{mV}$. The mean peak amplitude was $0.3 \mathrm{nA}$ and the decay was exponential with a decay time constant of $7.6 \mathrm{msec}$. This $\tau_{\text {MEPSC }}$ value is within the range of time constants obtained for EPSCs recorded in other cells voltage-clamped to $-90 \mathrm{mV}(8.8 \pm 2.1 \mathrm{msec})$.

Both EPSC amplitude and decay time course are voltage dependent in parasympathetic cells. Peak EPSC amplitude and $\tau$ are voltage dependent, with both increasing with hyperpolarization. Cells were voltage-clamped over the voltage range -30 to $-90 \mathrm{mV}$. In this voltage range the synaptic current-voltage $(I-V)$ relationship was linear as illustrated by the results in Figure 4, which were obtained from two different cells. In approximately onethird of the cells studied, it was possible to record EPSCs at positive voltages. For these cells the reversal potential for the EPSC, determined by interpolarization, was -4.0 $\pm 6.7 \mathrm{mV}(n=11)$. The voltage dependence of the EPSC decay $\tau$ could be described by the relationship:

$$
\tau(V)=a \exp (A V)
$$

where $a$ is the value of $\tau$ at $0 \mathrm{mV}$ and $A$ is the coefficient of voltage dependence. The average value of the coefficient of voltage dependence was $-0.0070 \pm 0.0025 \mathrm{mV}^{-1}$
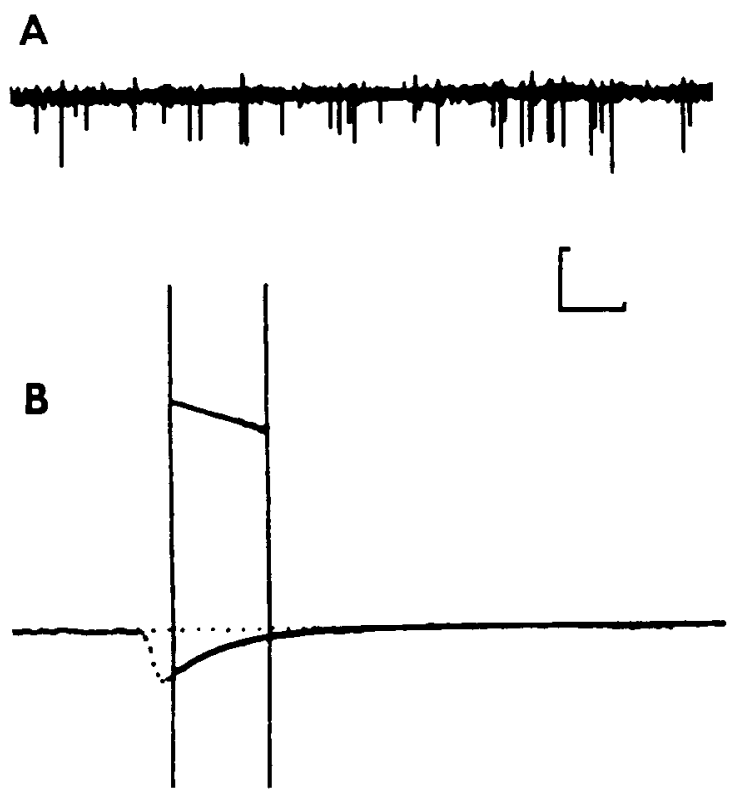

Figure 3. Examples of MEPSCs recorded in two different parasympathetic ganglion cells. $A, \mathrm{~A}$ series of MEPSCs recorded at $-60 \mathrm{mV} ; B$, an averaged MEPSC which represents the mean of 18 responses recorded in a cell voltage-clamped to $-90 \mathrm{mV}$. The decay phase of the averaged current is plotted semilogarithmically above the current trace. The vertical calibration equals $0.11 \mathrm{nA}$ (AC coupled) in $A$ and $0.35 \mathrm{nA}$ (DC coupled) in $B$. The horizontal calibration equals $2.5 \mathrm{sec}$ in $A$ and $8.8 \mathrm{msec}$ in $B$.
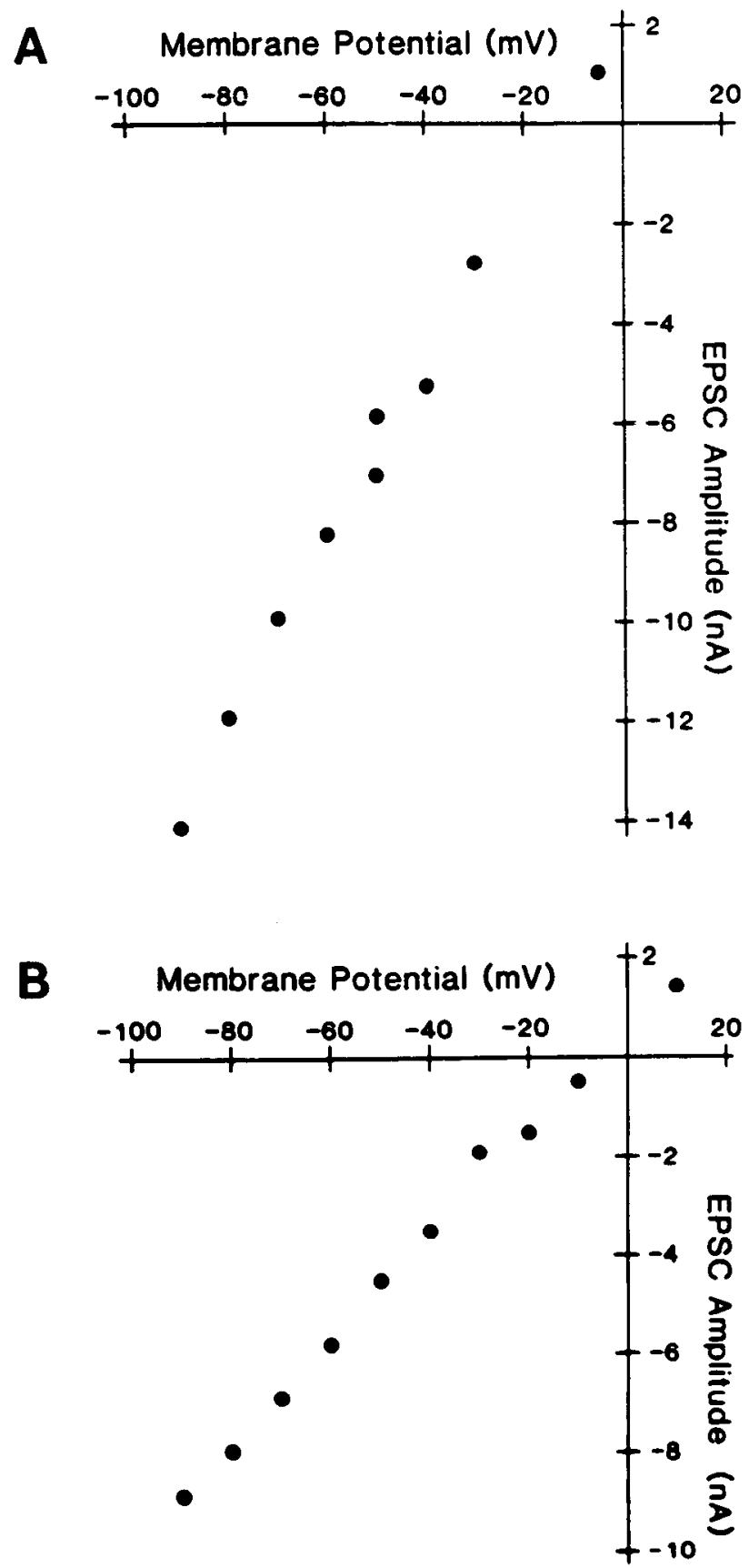

Figure 4. Examples of the peak EPSC-voltage relationship obtained for two individual parasympathetic ganglion cells. Generally, the $I-V$ curve was linear in the voltage range between -30 and $-90 \mathrm{mV}$. The data represented in example $A$ are from the same cell as in Figure 1. The temperature was 22 to $23^{\circ} \mathrm{C}$.

( $n=13$ ) at 21 to $23^{\circ} \mathrm{C}$. Values of $\tau$, for averaged EPSCs recorded from two different cells, are plotted as a function of voltage in Figure 5.

Parasympathetic cell EPSC decay is prolonged by MSF treatment. EPSCs were recorded from cells after a 1-hr treatment with the irreversible anticholinesterase agent, MSF. Following MSF treatment, EPSC amplitude was reduced and the decay time course was markedly prolonged. Furthermore, the decay phase deviated noticeably from a simple exponential function. These observations are illustrated in Figure 6, in which $A$ is an EPSC 

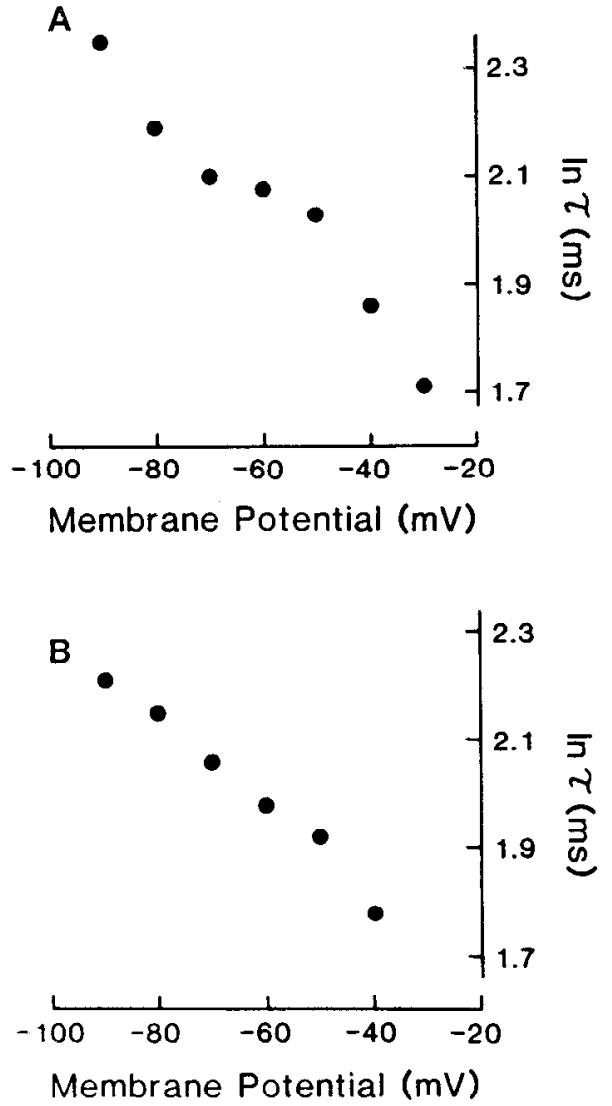

Figure 5. Semilogarithmic plot showing the effect of membrane potential on the EPSC decay $r$ for two different parasympathetic ganglion cells. The data represented in example $A$ are from the same cell as the records in Figure 1. The data shown in $B$ are from the same records as the $I-V$ curve in Figure $4 B$. The coefficient of voltage dependence was $-0.0078 \mathrm{mV}^{-1}$ in $A$ and $-0.0095 \mathrm{mV}^{-1}$ in $B$. The temperature was 22 to $23^{\circ} \mathrm{C}$.

\section{A}

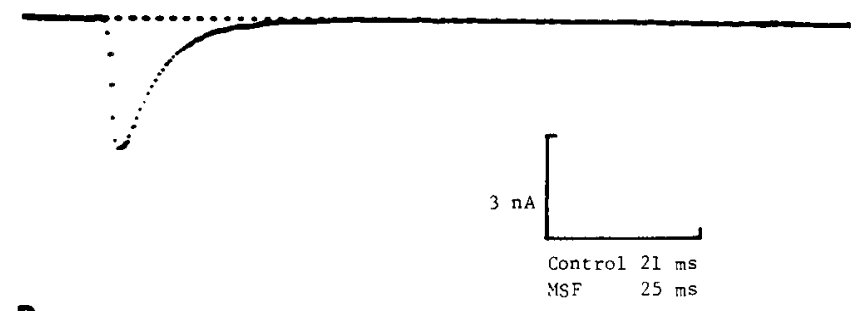

B

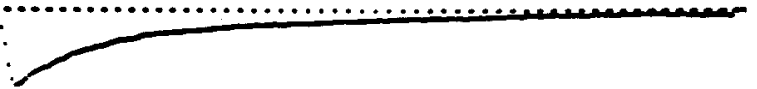

Figure 6. Averaged EPSCs from two different cells in the same ganglion preparation illustrating the prolongation of the current decay time course following MSF treatment. $A$, An averaged EPSC (six currents) from a control cell. $B$, An averaged EPSC (six currents) recorded in another cell following exposure to $10 \mathrm{~mm} \mathrm{MSF}$.

from a control cell voltage-clamped to $-50 \mathrm{mV}$ and $B$ is an EPSC recorded from another cell after MSF treatment in the same ganglion preparation, also voltageclamped to $-50 \mathrm{mV}$. To compare the EPSC decay time course in control and MSF-treated cells, half-decay time values were used rather than $\tau$ values because of the complex decay in the treated cells. In 12 control cells, the EPSC amplitude was $-3.6 \pm 1.5 \mathrm{nA}$ at $-50 \mathrm{mV}$ and the half-time of decay was $4.4 \pm 0.3 \mathrm{msec}$, whereas in five other cells following MSF treatment, EPSC amplitude at $-50 \mathrm{mV}$ was $-1.9 \pm 0.6$ and the half-time of decay was $10.7 \pm 3.4 \mathrm{msec}\left(23.5^{\circ} \mathrm{C}\right)$.

$E P S C$ decay $\tau$ has a $Q_{10}$ of approximately 3 . Additional experiments were done to determine the temperature dependence of the EPSC decay time course. Values of $\tau$ were obtained from different cells voltage-clamped to $-50 \mathrm{mV}$ over a temperature range of 13 to $23^{\circ} \mathrm{C}$. It was not possible to estimate $\tau$ at different temperatures in the same cell because of the limited time individual parasympathetic ganglion cells could be voltage-clamped. The results obtained from 24 cells are summarized in Figure 7 in which the natural logarithm values of $\tau$ are plotted as a function of temperature. The estimated $Q_{10}$ of $\tau$ was 2.9 .

EPSC amplitude also was sensitive to an alteration in bath temperature, with peak size decreasing with a reduction in temperature. For example, in five cells from one preparation, voltage-clamped to $-50 \mathrm{mV}$, the EPSC was $-5.1 \pm 1.1 \mathrm{nA}$ at 22 to $23^{\circ} \mathrm{C}$, whereas the average EPSC amplitude was $-2.7 \pm 0.6 \mathrm{nA}$ in six other cells from this preparation at $-50 \mathrm{mV}$ and 13 to $14^{\circ} \mathrm{C}$.

$A C h$-induced current fluctuations (noise) are well described by a single Lorentzian function. The properties of the ACh-gated channels in these parasympathetic ganglion cells were determined from an analysis of the increased current noise during steady iontophoretic application of ACh (Anderson and Stevens, 1973). Results were obtained from only a small percentage of cells studied for a number of reasons. First, it was difficult to obtain stable voltage clamp recordings at membrane polentials more negative than $-50 \mathrm{mV}$ for the length of time required to collect adequate noise records. Furthermore, because these cells did not tolerate being voltageclamped at values more negative than $-65 \mathrm{mV}$ for pro-

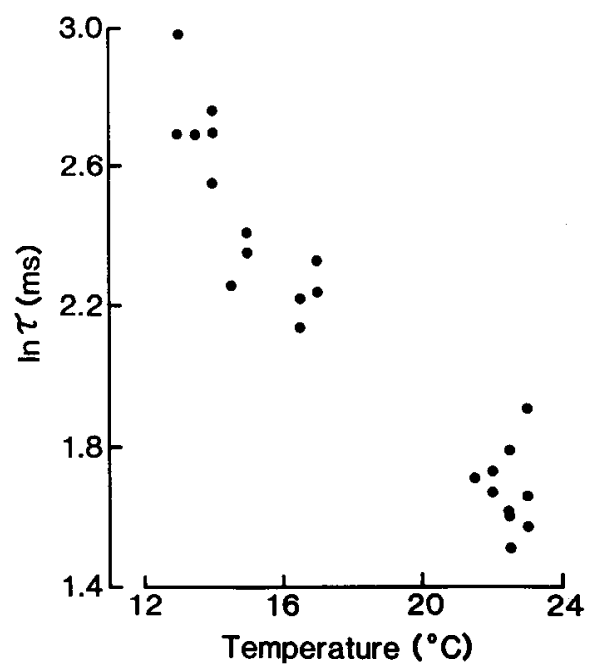

Figure 7. Logarithm of EPSC decay $\tau$ values from 24 cells voltage-clamped to $-50 \mathrm{mV}$ as a function of temperature. The slope of a linear regression using all data points indicated a temperature dependence of EPSC decay $\tau$ which had a $Q_{10}$ of 2.9 . 
longed periods, the DC shift and increase in noise during $\mathrm{ACh}$ application were small. This required that there be a very low, stable noise level prior to agonist application. Finally, it was not possible to increase the noise by simply increasing the magnitude of the iontophoretic current because of receptor desensitization. Although $\mathrm{ACh}$-induced noise was recorded from numerous cells, satisfactory results have been obtained in only six cells. In all instances, the current fluctuations could be fitted well by a single Lorentzian expression so that the mean channel lifetime, $\tau_{\text {noise, }}$ was obtained from the cutoff frequency of the spectra $\left(\tau_{\text {noise }}=\frac{1}{2 \pi f_{c}}\right)$. The results from one of these experiments are shown in Figure $8 A$. Iontophoretic application of $\mathrm{ACh}$ onto a cell voltageclamped to $-60 \mathrm{mV}$ produced a small inward current ( -3 nA) which developed within a few seconds to a steady level with a concurrent increase in the current noise. The spectral density for this response is shown in Figure $8 B$. The estimated cutoff frequency was $35 \mathrm{~Hz}$ which corresponds to a mean open time value of $4.5 \mathrm{msec}$. Single channel conductance, $\gamma$, was also estimated in these experiments. For the results presented in Figure $8, \gamma$ was estimated to be $13.6 \mathrm{pS}$. 'The estimates of $\tau_{\text {noise }}$ and $\gamma$

A

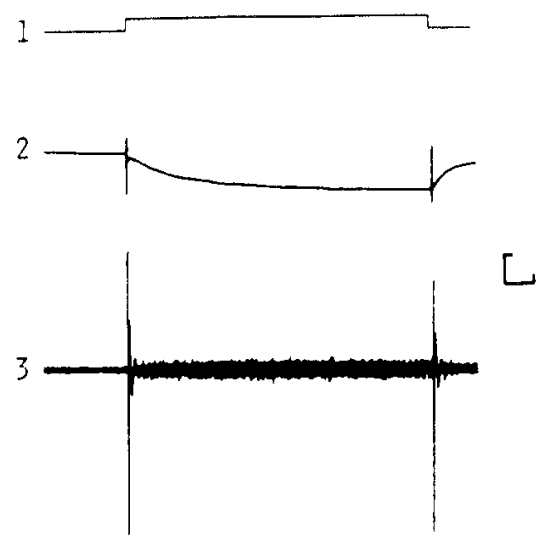

$\mathbf{B}$

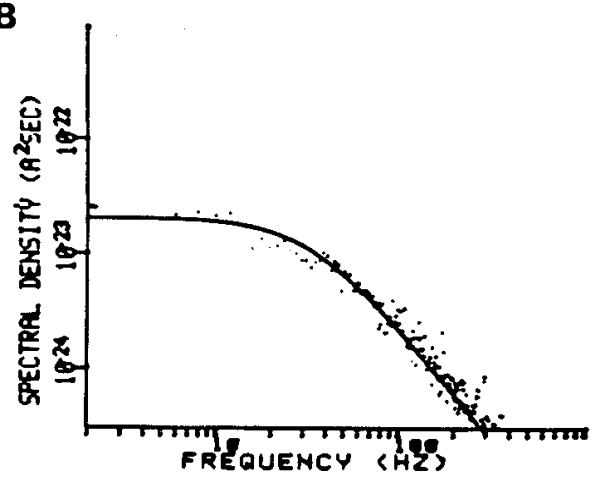

Figure 8. An example of an ACh-induced membrane current response in a parasympathetic cell voltage-clamped to $-60 \mathrm{mV}$. In $A, 1$ indicates the duration of the $\mathrm{ACh}$ application, 2 is the low gain, DC shift in membrane current, and 3 is the high gain, AC trace of membrane "noise." The vertical calibration equals $2.3 \mathrm{nA}$ in 2 and $0.11 \mathrm{nA}$ in 3. The horizontal calibration equals 2.5 sec. $B$ shows the spectral density plot of the current fluctuations from the record in $A$ (3). A Lorentzian function was fitted by eye; corner frequency, $f_{c}$, equal to $35 \mathrm{~Hz}$, zero frequency amplitude equal to $2.02 \times 10^{-23} \mathrm{~A}^{2}$ sec.
TABLE I

Single channel properties estimated from an analysis of current fluctuations

\begin{tabular}{ccccc} 
Cell & Membrane Voltage & $\tau_{\text {moise }}$ & \multicolumn{1}{c}{$\gamma$} & Temperature \\
\hline & $m V$ & $m s e c$ & \multicolumn{1}{c}{$p S$} & ${ }^{\circ} \mathrm{C}$ \\
1 & -60 & 4.1 & 8.9 & 23.0 \\
2 & -60 & 4.5 & 13.6 & 23.0 \\
3 & -50 & 4.9 & 9.7 & 23.0 \\
4 & -60 & 4.0 & 14.9 & 23.5 \\
5 & -65 & 5.6 & 5.4 & 23.5 \\
6 & -65 & 6.3 & 12.2 & 23.5 \\
\hline
\end{tabular}
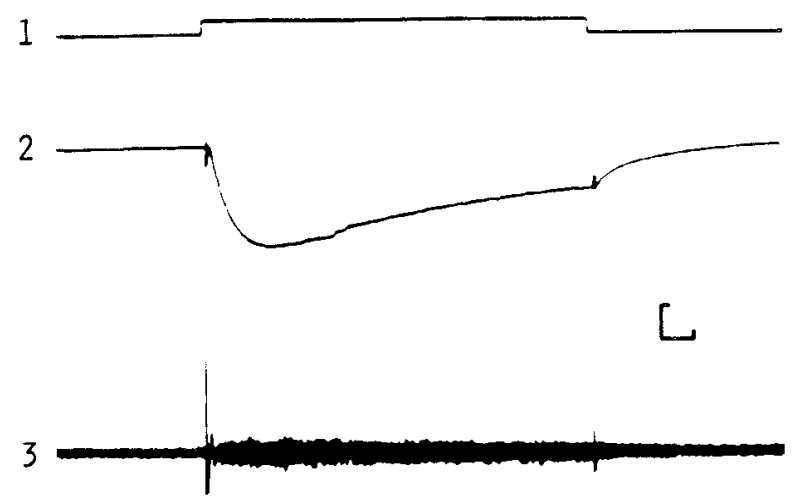

Figure 9. An example of an ACh-induced membrane current response which shows rapid desensitization obtained in a cell voltage-clamped to $-60 \mathrm{mV}$. Trace 1 shows the duration of the ACh application. The low gain DC shift (trace 2) and the magnitude of the membrane "noise" (trace 3) both fade with a similar time course. The vertical calibration equals $2.3 \mathrm{n} \Lambda$ in 2 and $0.11 \mathrm{nA}$ in 3 . The horizontal calibration equals $2.5 \mathrm{sec}$.

obtained ranged from 4.1 to $6.3 \mathrm{msec}$ and 5.4 to $14.9 \mathrm{pS}$, respectively. These results are summarized in Table I.

As indicated above, one problem encountered was that desensitization of postsynaptic receptors occurred rapidly in some cells during iontophoretic application of $\mathrm{ACh}$. One example of this is shown in Figure 9 in which $\mathrm{ACh}$ produced an initial inward current of $6.4 \mathrm{nA}$. The $\mathrm{ACh}$-induced current reached a maximum in about $5 \mathrm{sec}$ and then gradually declined. The magnitude of the membrane noise also decreased with a similar time course.

Bullfrog sympathetic and parasympathetic ganglion EPSCs exhibit very similar properties. In this study, we also have compared the general characteristics of EPSCs recorded from sympathetic and parasympathetic ganglion cells taken from the same bullfrog. The EPSC characteristics for both types of ganglion cells obtained under identical conditions in parallel experiments are summarized in Table II. Of the different properties analyzed, only the magnitude of the voltage dependence of the EPSC decay $\tau$ is noticeably different. We found that the EPSC decay is more voltage dependent in parasympathetic cells than in sympathetic cells.

\section{Discussion}

In the present study, the basic properties of fast excitatory synaptic currents recorded from amphibian parasympathetic and sympathetic ganglion cells have been compared. We conclude that most of the characteristics of the parasympathetic ganglion cell EPSC are very similar to those previously described for bullfrog sym- 
TABLE II

Comparison of EPSC characteristics recorded from sympathetic and parasympathetic ganglion cells

\begin{tabular}{|c|c|c|}
\hline & Parasympathetic Cells & Sympathetic Cells \\
\hline $\begin{array}{l}\operatorname{EPSC} \text { size }(\mathrm{nA}) \\
-50 \mathrm{mV}^{a}\end{array}$ & $-4.3 \pm 1.4(31)^{b}$ & $-6.3 \pm 2.3(15)$ \\
\hline EPSC decay ${ }^{a}$ & Exponential & Exponential \\
\hline $\begin{array}{c}\tau(\mathrm{msec}),-50 \\
\mathrm{mV}\end{array}$ & $5.6 \pm 1.0(31)$ & $5.0 \pm 0.9(15)$ \\
\hline $\begin{array}{l}\text { Voltage depend- } \\
\text { ence }\left(\mathrm{mV}^{-1}\right)\end{array}$ & $-0.0070 \pm 0.0025(13)$ & $-0.0039 \pm 0.0015(16)$ \\
\hline$Q_{10}$ & 2.9 & 3.1 \\
\hline $\begin{array}{l}\text { Reversal potential } \\
\qquad(\mathrm{mV})\end{array}$ & $-4.0 \pm 6.7(11)$ & $-5.0 \pm 5.1(24)$ \\
\hline \multicolumn{3}{|l|}{$\begin{array}{c}\text { Alteration by MSF } \\
\text { treatment }{ }^{a}\end{array}$} \\
\hline $\begin{array}{l}\text { Decrease in } \\
\text { EPSC size }\end{array}$ & $\sim 45 \%$ & $\sim 40 \%$ \\
\hline $\begin{array}{l}\text { Increase in } \\
\text { EPSC half-de- } \\
\text { cay time }\end{array}$ & $\sim 240 \%$ & $\sim 170 \%$ \\
\hline
\end{tabular}

${ }^{a}$ Values obtained with bath temperature between 22 and $23^{\circ} \mathrm{C}$.

${ }^{b}$ Numbers in parentheses, number of cells.

pathetic ganglion B cells (Kuba and Nishi, 1979; MacDermott et al., 1980). However, the EPSC decay is more voltage dependent in amphibian parasympathetic than in sympathetic cells, with the voltage-dependent coefficient of $\tau$ in parasympathetic cells being closer to that reported for vertebrate twitch muscle (Magleby and Stevens, 1972a; Anderson and Stevens, 1973; Dionne and Parsons, 1981) and mammalian sympathetic ganglia (Selyanko et al., 1979). In contrast to bullfrog parasympathetic EPSCs, the EPSC decay in rat parasympathetic cells is reported to be more complex, the decay time course consisting of two exponential components (Rang, 1981). Furthermore, analysis of $\mathrm{ACh}$-induced current fluctuations in rat submandibular cells required two Lorentzian components which corresponded closely to the two EPSC decay components (Rang, 1981). In contrast, current fluctuations recorded here in the bullfrog parasympathetic cells were well described by a single Lorentzian function with the estimated value of the mean channel open time very similar to the EPSC decay time constant (compare data in Table I and Fig. 7). These differences suggest that there may be characteristic properties for EPSCs in parasympathetic ganglia from different species, e.g., amphibian versus mammalian preparations. It is interesting that the decay characteristics of EPSCs recorded from mammalian sympathetic ganglion cells very closely resemble those of the amphibian ganglion cells (Selyanko et al., 1979).

We also observed in these amphibian parasympathetic cells that MEPSC decay was exponential with a time constant similar to that of the EPSCs recorded at the same voltage. MEPSC size in these amphibian ganglion cells generally was very small, being similar to that reported for other vertebrate ganglion preparations (Selyanko et al., 1979; Rang, 1981). This represents an obvious difference between MEPCs recorded at the vertebrate motor endplate and the ganglion MEPSCs, the former being at least 10- to 20-fold greater in magnitude (Anderson and Stevens, 1973; Dionne and Parsons, 1981).
It was observed, in a small percentage of cells, that the EPSC decay was not adequately described as a single exponential function. Although this deviation was not marked, a better fit was obtained when the decay phase was described as the sum of two exponential components. Two alternative explanations for this complex decay in these few cells are considered here. First, the two components may represent the contribution to the total current decay of two kinetically distinct channels with different mean channel open times, an explanation similar to that proposed for the two-component decay in rat parasympathetic ganglion cells (Rang, 1981). Alternatively, the complex decay may represent the response of dually innervated cells in which the two synaptic inputs are distant: one primarily on the soma, the other further away on the axon. Dual innervation of this nature in these cells is well documented (McMahan and Kuffler, 1971). The slower "tail" component in the EPSC of these cells would represent the attenuated antidromic invasion of the synaptic response into the somal region. We favor the latter alternative, although more information is required before the question can be answered unequivocally.

MSF treatment lengthened the EPSC decay and decreased the peak EPSC size in both parasympathetic and sympathetic cells (Table II). At the motor endplate MSF is a potent anticholinesterase agent (Adams and Sakmann, 1978). MSF was used in the present study because we found previously that, in the presence of both neostigmine and physostigmine, EPSC decay in sympathetic ganglion cells was complex (MacDermott et al., 1980). The EPSC decay in MSF-treated cells also could not be fitted by a single exponential function. The decay in MSF did not exhibit a clear fast and slow component as occurs in physostigmine-treated preparations; rather, the decay time course more closely resembled that of neostigmine-treated sympathetic ganglion cells. The decrease in peak EPSC amplitude following MSF treatment was an unexpected finding. It could result from either a decrease in transmitter release or a decrease in postsynaptic sensitivity to ACh. The results obtained in this study do not distinguish between these possibilities. However, the present results reinforce the conclusion reached earlier that anticholinesterase agents may have direct effects on nicotinic channel kinetics on postganglionic cells in addition to their anticholinesterase activity (MacDermott et al., 1980).

The $Q_{10}$ for the EPSC decay in the parasympathetic cells was approximately 3 , a value similar to that observed at numerous other synapses (Magleby and Stevens, 1972b; Anderson and Stevens, 1973). This observation demonstrates that "free" transmitter diffusion within the synaptic cleft does not normally determine the EPSC decay time course.

Estimates of mean single channel conductance for the parasympathetic ganglion cells ranged from 5 to $15 \mathrm{pS}$, values less than that observed at other nicotinic synapses (Anderson and Stevens, 1973; Dionne and Parsons, 1981; Rang, 1981; Schofield et al., 1982). The magnitude of the iontophoretic current required to produce measurable DC shifts in the membrane current of parasympathetic cells was larger than that required to produce a much more substantial current shift at the motor endplate of 
skeletal muscle under identical conditions (Dionne and Parsons, 1981). This observation supports the suggestion made previously by Rang (1981) that the density of receptors on the postganglionic cells may be lower than at the muscle postjunctional membrane. As a result the agonist concentration in the synaptic cleft may have been high, resulting in an underestimate of $\gamma$. The fact that desensitization often occurred rapidly in these parasympathetic cells even though the agonist-induced current was only a few nanoamperes is consistent with this view.

The similarity between the EPSC and MEPSC decay time constants and the estimated mean channel open time from ACh-induced noise confirm that, for amphibian parasympathetic ganglion cells, the time course of EPSC is determined by the kinetics of receptor-channel gating rather than the kinetics of transmitter release or time course of ACh removal by diffusion or hydrolysis. Furthermore, the similarity between the basic characteristics of fast synaptic currents at amphibian parasympathetic and sympathetic ganglion cells suggests that the kinetics of receptor-channel gating determine the time course of EPSC decay at both ganglionic synapses.

\section{References}

Adams, P. R. (1982) Voltage-dependent conductances of vertebrate neurones. Trends Neurosci. 5: 116-119.

Adams, P. R., and B. Sakmann (1978) A comparison of currentvoltage relations for full and partial agonists. J. Physiol. (Lond.) 283: 621-644.

Anderson, C. R., and C. F. Stevens (1973) Voltage clamp analysis of acetylcholine produced end-plate current fluctuations at frog neuromuscular junction. J. Physiol. (Lond.) 235: 655-691.

Connor, E. A., S. M. Levy, and R. L. Parsons (1983) Kinetic analysis of atropine-induced alterations in bullfrog ganglionic fast synaptic currents. J. Physiol. (Lond.) 337: 137-158.

Connor, E. A., and R. L. Parsons (1983) Procaine alters fast excitatory postsynaptic current decay in amphibian sympathetic ganglia. Br. J. Pharmacol. 78: 293-299.
Dennis, M. J., A. J. Harris, and S. W. Kuffler (1971) Synaptic transmission and its duplication by focally applied acetylcholine in parasympathetic neurons in the heart of the frog. Proc. R. Soc. Lond. Biol. 177: 509-539.

Dionne, V. E. (1976) Characterization of drug iontophoresis with a fast microassay technique. Biophys. J. 16: 705-717.

Dionne, V. E., and R. L. Parsons (1981) Characteristics of the acetylcholine-operated channel at twitch and slow fibre neuromuscular junctions of the garter snake. J. Physiol. (Lond.) 310: $145-148$.

Gage, P. W., and R. N. McBurney (1975) Effects of membrane potential, temperature and neostigmine on the conductance changes caused by a quantum of acetylcholine at the toad neuromuscular junction. J. Physiol. (Lond.) 244: 385-407.

Kuba, K., and K. Koketsu (1978) Synaptic events in sympathetic ganglia. Progr. Neurobiol. 11: 77-169.

Kuba, K., and S. Nishi (1979) Characteristics of fast excitatory postsynaptic current in bullfrog sympathetic ganglion cells. Effects of membrane potential, temperature, and $\mathrm{Ca}$ ions. Pflügers Arch. 378: 205-212.

MacDermott, A. B., E. A. Connor, V. E. Dionne, and R. L. Parsons (1980) Voltage clamp study of fast excitatory synaptic currents in bullfrog sympathetic ganglion cells. J. Gen. Physiol. 75: 39-60.

Magleby, K. L., and C. F. Stevens (1972a) The effect of voltage on the time course of end-plate currents. J. Physiol. (Lond.) 223: 151-171.

Magleby, K. L., and C. F. Stevens (1972b) A quantitative description of end-plate currents. J. Physiol. (Lond.) 223: 173-197.

McMahan, U. J., and S. W. Kuffler (1971) Visual identification of synaptic boutons on living ganglion cells and of varicosities in postganglionic axons in the heart of the frog. Proc. $R$. Soc. Lond. Biol. 177: 485-508.

Rang, H. P. (1981) The characteristics of synaptic currents and responses to acetylcholine of rat submandibular ganglion cells. J. Physiol. (Lond.) 311: 23-55.

Schofield, G. G., F. F. Weight, and M. Adler (1982) Single nicotinic acetylcholine induced ionic channel currents in bullfrog sympathetic ganglia. Soc. Neurosci. Abstr. 8: 945.

Selyanko, A. A., V. A. Derkach, and V. I. Skok (1979) Fast excitatory postsynaptic currents in voltage-clamped mammalian sympathetic ganglion neurons. J. Auton. Nerv. Syst. 1: 127137 . 